\title{
The Economic Aspects of Human and Child Sacrifice
}

\author{
Peter Rwagara Atekyereza1,a , Justin Ayebare ${ }^{2, b}$, Paul Bukuluki ${ }^{3, c}$ \\ 1Department of Sociology and Anthropology, Makerere University, Kampala, Uganda \\ ${ }^{2}$ Faculty of Education, St. Lawrence University, Kampala, Uganda \\ ${ }^{3}$ Department of Social Work and Social Administration, Makerere University, Kampala, Uganda \\ a,b,c E-mail address: atekyereza@ss.mak.ac.ug , ayebare@hotmail.com , \\ pbukuluki@ss.mak.ac.ug
}

\begin{abstract}
The understanding of child sacrifice requires the broader understanding of the history, context of and rationale for the concept of sacrifice in all its forms including human sacrifice. Historically, sacrifices were made to atone for sins or wrong-doing and to ask for blessings. The forgiveness was for or blessings included but were not limited to material wealth (particularly land, domestic animals and other tangible possessions), children, health, and prosperity. In spite of the variations in understanding sacrifice, common to all is the underlying guiding principle of the value for value. It means the higher the value of the blessings to be sought or wrongs to be atoned, the higher the value of the sacrificial item. Overtime, this principle has been expressed in varied forms including human sacrifice, in general, and child sacrifice, in particular. These practices are closely associated with dominant cultural value systems that people hold in relation to what is important in life and how to get it. Despite economic progress of economies characterised by sophisticated wealth computations, predictions and protection through insurance, sacrifices remain part of the social fabric for solicitation, utilisation, maintenance and protection of wealth. This chapter, therefore, broadly analyses and explains the role of economic structures and institutions on society and the influence of society on the nature of economic structures and institutions. Though there is no established scientific basis for a correlation between human sacrifice and wealth acquisition, the sacrificial items are goods of high economic value and they bring economic returns to those involved in their exchange. It is important to explain how economic wealth creates and is further re-created by sacrifices, particularly, human sacrifice. Human sacrifice is strongly dominated by child sacrifices which are believed to be without blemish and of higher atoning value. Any attempt to destroy the practice of human and child sacrifice for wealth acquisition must first destroy the dominant cultural mentalities or values systems on which they are based.
\end{abstract}

Keywords: Sacrifice; capitalism; human sacrifice culture

\section{INTRODUCTION}

It is documented that sacrificing evolved and spread with the development of various religious practices (Narasimha, 1998). However, the fundamental incentive for sacrificing in general and human and child sacrifice, in particular, is to live a better life characterised by personal health and material possessions. The oral and written literature on societies in African and elsewhere demonstrates that wealth was revered and poverty scorned (Atekyereza, 2011; Nzita and Mbaga, 1997; Mmumuhungirehe, 1984; Achebe, 1960 and 1958). This reality is still 
prevalent. The rich always command more social acceptance than the poor. It is this practice which has always compelled human beings to strive for material acquisition and success. This was normally reflected in material wealth and health (particularly human reproductive capacity) - the two always re-enforced each other. In the pursuit of socio-economic success, people performed different rituals searching for success and retaining it. Sacrifices were originally understood in this respect. Sacrifices were made for atonement of wrong doing so that one remained at peace with the gods and neighbours for more blessings which would include economic success.

The socio-cultural and religious value of the sacrifice was linked to the corrective measures or atonement for wrong-doing. In other instances, it would be for seeking blessings. The more valuable the request the more expensive the sacrificial item would be. Originally, these items of sacrifice ranged from chicken to livestock like goats, sheep or cows. The idea of human sacrifice was not well documented. The Christian and Islamic literature report God or Allah requesting Abraham to sacrifice his only son Isaac (Genesis 22:1-19). In explaining the context in which it happened, the literature does not portray that God or Allah accepted child sacrifice. The request was based on the covenant that God or Allah had made with Abraham. This experience clearly portrays the cardinal principle in human and other forms of sacrifice i.e. the logic of value for value principle. It demonstrates how this principle has been evolving gradually within society across time and space reflected in the changing periods and processes of wealth creation, acquisition and accumulation at individual, family and community levels. It is from this perspective that the chapter describes analyses and explains the economic aspects of child sacrifice.

\section{WEALTH CREATION, ACQUISITION AND ACCUMULATION}

Though the understanding of wealth varies across societies at different times of history, in economic terms, the definition of wealth is maintained as anything of value. According to the Economic Glossary (2008), wealth includes all of the tangible possessions, financial assets and ownership of resources such as labour, capital, and natural resources. It means ownership of material possessions and productive resources. The value in this possession lies in the ability to satisfy a need. However, value or utility is a highly subjective and variable concept. Right from the works of the Economics classics like Adam Smith (1776) in The Wealth of Nations, through Karl Marx and his analysis of wealth accumulation and the development of social classes to Max Weber in The Protestant Ethic and Development of Capitalism (Coser, 1977), to the current authorities on and/or architects or critics of global capitalistic monetary economies (such as the Breton Woods institutions (the International Monetary Fund (IMF), World Bank (WB) and Chang, 2010). It is evident that material wealth acquisition and accumulation has been central to the definition of social existence. Whereas wealth refers to accumulation of resources irrespective of its volume or size, richness refers to abundance of such resources. A rich person is deemed to be the one with more economic and financial resources. A poor person has fewer resources. Logically, the rich have more capacity than the poor to meet their basic needs and those of their families or dependants. The desire to accumulate resources has always been and continues to be central to human and societal existence. However, the normative processes of acquiring, accumulating, protecting and utilizing these resources and ethical implications of such processes differ from society to society. Human and child sacrifice reflect specific normative processes of human existence including those related to wealth acquisition, accumulation and utilization. 


\section{THE HISTORICAL ECONOMIC CONTEXT OF CHILD SACRIFICE}

Whenever the word child sacrifice is mentioned, the quickest things that run through one's mind are kidnap, rituals, body mutilation, blood, killing, murder, witchcraft, etc. However, in connection with these perceptions, people always ask why people kill or sacrifice innocent children. The understanding of child sacrifice cannot be taken out of the broader context of the ritual of sacrifice and of human sacrifice in general. The term sacrifice derives from a Latin word sacrificium that means the act of offering the life of an animal, a person or some object to God or the gods in order to appease or atone for one's wrong doing and thereafter seek favour or for worship (Guralnik 1986: 1252). The acceptability of the sacrifice depends on acceptability of the items that are sacrificed. A sacrifice oftentimes implies killing though there are also bloodless sacrifices based on, for example, food items like cereals and beverages. Anything of some value could be a sacrifice in religious practices. Generally, the more valuable the offering, the more highly the sacrifice is regarded but the more difficult it is to make. On a day-to-day basis, offerings may be quite simple, for example, in form of flowers, candles, incense, spilling some of the drink from a cup before drinking, etc. In yet another reference to the old testament of the Christian Holy Bible the cost of offering a sacrifice was actually quite significant. Removing an unblemished cock, lamb, goat, or bull from one's flocks was definitely a substantial cost though it might not have been monetary. In essence, sacrifices were a form of protection or insurance.

As society gradually changed, forms of wealth and the way it was acquired and protected changed just as the ways in which it was expressed. The forms or ways of securing this wealth changed from religious sacrifices to more economic and business-oriented forms of physical and human protection. Today, we have the formal economic or business insurance system for the same purpose. Traditionally in most African communities, security of homesteads and the people and property therein depended on the power of the head of the extended family to negotiate for peace with the gods to be spared of long spells of draught, floods, epidemics and pest plagues like locusts. Taking the example of wealth in form of shelter, houses were very simple structures of grass and sometimes with mud and wattle walls. In such houses, people basically co-existed with the rest of the nature in its diverse forms. People lived with very ferocious animals like leopards and snakes but believed that as long as the gods were at peace no harm would befall them. Such houses did not pose much climatic contradictions or clashes arising from contraction or expansion of the building materials like is the case in countries that experience extreme hotness or coldness (summer or winter, respectively).

If a house fell or was blown by the winds or hailstorms, it was easy to replace because the raw materials were easily available and accessible. Gradually the human population increased along with new forms of needs and the evolving ways to satisfy them. The need for shelter has evolved from simple house structures to now very huge, highly raised and costly skyscrapers. The cost of such materials is very expensive. Accessibility to such materials is not only hard but equally expensive. The forms of exchange are now dominantly based on money. The dangers or risks to such buildings are not only much higher and only nature-prone but also quite complicated due to additional man-made or engineered causes like civil or armed conflict, fire, architectural design faults, faulty building materials, poor workmanship, etc. The economists have thus evolved the banking and insurance systems to manage such risks. The 
higher the value of the asset or property the higher the insurance premium ${ }^{1}$. The higher and more likely and serious the risk, the more the insurance premium.

It should be noted that this insurance principle is similar to the Biblical or Qur'anic sacrifice principle i.e. equal value principle. Furthermore, whereas we are in the modern or post-modern times, the behavioural tendencies in pre-industrial times are still in existence including sacrifice rituals. There is a strong belief among the people who practise ritual sacrifices that the sacrifices reduce either the likelihood of occurrence or intensity of risks. There is also low understanding or appreciation of the role and value of formal insurance even among the more educated. This partly explains why very few people today have taken up or are willing to insure their lives or property against highly predictable risks like accidents, sickness or fire. The discussion of child sacrifice should therefore be seen from the perspective of protection against risks or promoting healthier physical and economic lives.

\section{THEORETICAL FRAMEWORK OF UNDERSTANDING THE ECONOMICS OF CHILD SACRIFICE}

\section{Evolution of Economic sociology}

The economic rationale of life generally has been changing throughout history depending on the dominant cultural and economic factors that influence people's meaning of life and their subsequent interactions with each other for social and individual purposes. During the late Seventeenth century, one classic Auguste Comte (1798-1857) believed to be the father of sociology, explained that there are two key pillars in society that influence its functioning and subsequent stability and social order. He named these pillars social statics and social dynamics (Ritzer and Goodman 2004, Ritzer 1992, Coser 1977). Whereas the social statics refer to society's institutional framework highly critical for social stability and continuity, the social dynamics refer to the rules, regulations and guidelines that allow the functioning of the institutions. It is such dynamics that allow for social change in value systems and functioning of society. The purpose of institutions and the rules and regulations therein is to control the selfish motives of human beings including the unlimited personal craze for wealth accumulation and utilisation. Comte believed that the nature and functioning of these pillars is different during the different stages of a unilinear model of human evolution that he identified as the theological, metaphysical and lastly scientific. Upon reaching the scientific stage, the previous misguided knowledge based on uttermost belief in the supernatural beings or the metaphysical/personified abstract forces would be dropped in favour of scientifically proven knowledge. In this case, the modern formal insurance system would have completely replaced all types of sacrifices as means of protection of physical or business life against all possible risks.

In reaction to this Comtean unilinear model of social change, Pitirim Sorokin (1889-1968) (Coser 1977) counter-argued that changes in society are cyclic because of the dynamic nature of social interaction processes and the different dominant cultural mentalities at different times of human history. Sorokin saw human interaction as a process that involves human beings as actors of interaction and that their conduct was guided by cultural meanings, values and norms. Most importantly, he noted that material phenomena are vehicles through which meanings and

\footnotetext{
${ }^{1}$ An insurance premium is the actual amount of money stipulated by an insurance company that a insurance policy holder must pay in order to maintain the active coverage of an insurable risk. An insurance premium for the same service can vary widely among insurance providers. Whereas the lowest quoted price on an insurance premium may be the better bargain, the level of coverage may also be lower.
} 
values reflected in a sequence of human actions. Hence, when social phenomena are stripped of their culture or meaningful aspects, they become meaningless. Though no culture is ever fully integrated, socio-cultural phenomena are based on relatively coherent and integrated aggregates of cultural perspectives, which influence meanings on specific periods of human history. Sorokin argued that reality of the world around us may be felt directly through our senses (the sensate culture). In this case, life becomes only meaningful when we can sensually experience especially the material and physical word. Alternatively, it can be felt through a view that transcends the world of senses - the world of eternal (ideational culture) comparable to the Platonic idealism and in this case the material world is less important compared to the anticipated life hereafter.

However, the third cultural mentality provides a mid-point between the first two mentalities and tries to rationalize the two opposing principles (the idealistic culture). Important to note is the fact that the three major types of cultural mentalities reveal three concrete truths i.e. the sensory, spiritual and rational. In society, social change (including the beliefs and value systems related to sacrifice in general and human child sacrifice in particular) moves in a cyclic form and the dominant themes of any of the three major cultural mentalities are bound to repeat themselves in history though not as exactly as they happened in the previous cycle. At different periods of human history, one of the three basic premises achieves more prominence over the others in the way it influences the thinking, feelings and actions to the extent that even the principal institutions of society (such as the law, art, and philosophy) come to reflect this predominance. Hence, unlike Comte who believed that value systems in earlier phases of society's transition would never come back once society reached the scientific and rational stage, Sorokin's argument is that the such value and belief systems (like those that pertain to human sacrifices) remain though saliently. From Sorokin's analysis it is possible to see why people still believe in the power of sacrifices to protect them against harm or risks and offer them blessings including economic opportunities even when we live in a modern, rational and scientific society.

Later on Karl Marx (Coser 1977, Ritzer 1992, Ritzer and Goodman 2004) and other conflict theorists argued that the pace and direction of the human society was due to the unequal access to vital resources which results in different groups having different interests. As a result of this socio-economic and political inequality, society is always characterised by conflict over how to access and utilise the available vital resources for human sustenance. In a fully developed capitalistic economy the acquisition, accumulation and protection of wealth is through exploitation of the less powerful social groups especially the workers for the three cardinal economic processes of saving, investment and consumption. Such exploitation is believed to result in concentration of the basic production resources (including political power) in the hands of very few people. Human and child sacrifice is believed to facilitate and protect this process or assist the poor or powerless to break the status quo. This view may partly explain the commonly media-reported public feeling that there are people in government that are protecting those economically powerful persons believed to be involved in child sacrifice (see Nsambu and Mambule, 2010).

However, Emile Durkheim (Coser, 1977) argued that the conflict inherent in society is due to the sudden social change in society and the resultant social anomie during adaptation. Robert Merton took this concept further using the Strain Theory and argued that the real problem is not created by sudden social change but by a social structure that holds out the same goals to all its members without giving them equal means to achieve them. So it is this lack of integration between what cultural or societal expectations and what the structure permits that causes deviant behaviour like human child sacrifice. Societal expectations are, for example, 
reflected in healthy living, formal education, permanent houses, powerful four-wheel vehicles, powerful positions in government or non-government organisation, huge chunks of land, etc. Society emphasizes certain goals and the means to reach such goals (for example, education, hard work, employment, incomes etc.).

However, due to differential access to productive resources or opportunities to achieve these goals, some people use unconventional means (including socially deviant practices like child sacrifice) to meet these expectations. This disconnection results in the breakdown of rules on social behaviour and subsequently people will not know of what to expect from each other. In this reference, most of the cases of child sacrifice implicate the older persons whom the children believe in for their protection and support such as relatives, guardians, neighbours and even biological parents (ANPPCAN, 2009). It is such a situation that Durkheim called anomie or normlessness or the war-of-al-against-all; a state where norms (behavioural expectations) are confused, unclear or not present.

Furthermore, the situation is further exacerbated by fact that though there is a social structure reflected in the legal and judicial system, it is deemed not to punish the child sacrifice culprits enough or the enforcement structures are very weak or absent. In Uganda, the 1957 Witchcraft Act prohibits acts of witchcraft that involve threatening others with death ... "any person who directly or indirectly threatens another with death by witchcraft or by any other supernatural means commits an offence and is liable on conviction to imprisonment for life." The Act also prohibits acts of witchcraft ... "any person who practices witchcraft or who holds himself or herself out as a witch, whether on one or more occasions, commits an offence and is liable on conviction to imprisonment for a period not exceeding five years". However the law has rarely been enforced, reducing its deterrent and retributive functions against those involved in witchcraft practices, particularly those which involve human sacrifice. Furthermore, child sacrifice is not punishable under the Uganda constitution.

In addition to this, however, the social exchange theory based on economic rationality and building on the symbolic interactionist perspective posits an argument that human interaction is based on expected economic gains. People will invest more of their efforts in relationships or activities that they believe will bring them equal or more returns than they invested (Ritzer ...). So it may make economic sense to sacrifice a child bought at Uganda shillings $600,000 /=$ (i.e. about USD 200.-) to insure or ensure that an investment brings in more returns than the Uganda shillings $600,000 /=$ though this anticipated economic return has no scientific evidence. Under lack of law enforcement, some people believe that whatever makes financial gain or difference irrespective of the how is economically justifiable. To such people, the human value of the child is superseded by the financial or material value. This may explain what Joseph Schumpeter (1934 cited in Alvarez, Agarwal and Soreson, 2005: 82) explained as competitive destruction where people only value whatever brings in or is believed to bring in money irrespective of the ethical considerations or implications in order to survive the capitalist competition for profit (see also Bradley 2009: 120, Alvarez, Agarwal and Soreson 2005: 82). This is similar to the Eco (2012) finding that many Ugandan communities have embraced materialism as a core value. People earn respect and recognition in their communities because of the wealth they possess. The adoption of wealth as a value has driven some people to seek means of acquiring possessions at all costs. 


\section{CHILD SACRIFICE FOR ECONOMIC GAIN IN UGANDA}

According to EACO Uganda (n.d.), there are four key economic factors in offsetting and sustaining child sacrifice. The various actors in child sacrifice rituals usually have economic interests: defined as the desire for wealth and business prosperity; insurance; poverty and trickery or fraud by traditional healers. The explanations for those desiring to have wealth or business prosperity and escape from poverty as well as protection of such wealth or its insurance appear to be related. Furthermore, the processes of trying to acquire wealth and its protection or escape from poverty are characterized by treachery and fraud.

There are different means of acquiring and protecting wealth or avoiding poverty which are ethically correct and socially acceptable and those that are not. Wealth may be acquired or poverty may be avoided through saving and investments as well as through employment. Different societies have continued to exhibit different indicators of what is perceived to be economic wealth. These indicators have been changing over time depending on the political economy of the time. We shall now show the manifestations of the economics of child sacrifice in Uganda in relation in a few selected aspects. Such actions have an impact on the economy while the resultant economic realities may further fuel child sacrifice. Whereas in modern industrialized or industrializing economies people are expected to have had formal education and exposure to science and to have abandoned the cultural value systems characteristic of traditional subsistence agrarian economies, such behavioural tendencies still exist including sacrificing and not necessarily based on scientific explanations and predictions. Most reported child sacrifices are associated with house construction, industrial machinery installation, electric power dam and road constructions as well as employment (Vernaschi, 2010).

In terms of house construction, many builders have always asked animals like chicken or a goat or sheep depending on the size of the house to slaughter during foundation breaking or making. It is claimed by such workers that if they do not slaughter something with blood, there will be accidents during construction (Enyumba bweba tesaliddwa yeesalira meaning if the house is not slaughtered for it slaughters for itself by killing a person during or after construction $^{2}$. Though most people do not call it a sacrifice, they perform such rituals to avert any undesirable eventualities. If the house is for rental or commercial purposes, the person making the sacrifice is interested in securing or protecting the investment against misfortunes like troublesome tenants especially when it comes to payment, protection against law enforcement agents e.g. city authorities monitoring for licences, collapsing of the buildings and against fire. On the other hand, the sacrifice is believed to catalyse timely tenants and payments. In case of business, it is believed to bring in more paying clients or customers compared to their competitors and access to better or more economically rewarding deals. Hence, on one hand, the economics of child sacrifice do not lie in the child sacrificed but in the cost of transactions or treachery that precede the decision on the sacrifice. On the other hand, the economics may relate to the belief that the value of the child will translate into equal or even more economic outcomes through the opportunities created and misfortunes survived or averted like the social exchange theory argues.

In the context of light and heavy industrial machinery, it is believed that if valuable sacrifices are not made, machines will either constantly break down or not bring in the desired and timely profits and this will subsequently results in business losses. Given this line of thought, it may not be surprising that even under the current mechanical/electrical faults arising from electric power fluctuations, people still believe that once sacrifices are made, there will be

\footnotetext{
${ }^{2}$ Personal Conversation with a house builder in Kampala, Uganda in February 2003.
} 
less load shedding or less damage to their machinery. There is a widely held belief, for example, that most children are sacrificed during the installation of heavy factory or industrial machinery or during the construction of bridges and electric power dams. Given the ongoing transition of the Ugandan economy from that heavily dependent on agriculture to an industrial one, then the prediction would be that more children are yet to be sacrificed if such beliefs persist.

Related to the above is the human and child sacrifice for highways, bridge, tunnels and dam constructions. The explanations for such practices are enshrined in the beliefs that people hold. Writing about the Maya of southern Mexico and northern Central America, for example, Molesky-Poz (2006: 102) explains that the ancestors while interacting with the land configured the earth not only as a spiritual territory or cultural landscape, but also as sacred and living. The sacrifice in this case is understood as a survival strategy for acknowledging the earth and honouring its vital forces. A sacrifice is seen as a necessary practice to establish equilibrium with the earth although it is transformed in practice and nature. Molesky-Poz (2006: 104) argues that human sacrifices were presented to a place to stabilise the construction of bridges, dams, roads and tunnels. He explains some Maya perceived the acts of construction, such as changing the course of the river or building a highway, as violent disturbances of the earth and believe that the Owner needs sacrifices to be compensated for the injury. Further they believe that to accomplish good works for construction projects to be stable, "the sacred earth, the sacred place, needs a present".

Such beliefs are not very far from those held by Ugandans. Given that most construction companies for roads, dams and bridges are not indigenous, it is not easy to know their beliefs but they may not deviate much from those held and influencing practices in Uganda. There is, for example, a widely told story that the engineer who constructed the bridge across river Rwizi in Mbarara Town sacrificed his finger before the bridge could be completed. He was finally known as Ngaro Mwenda! (nine fingers instead of ten). Going by Molesky-Poz's (2006) explanation, it is logical to deduce that the many road, dam and bridge constructions in the country could have fuelled child sacrifice in the country.

When it comes to motor vehicles, the anticipated economic gains from child sacrifice depend on the purpose of the vehicle. The economic rationale of commercial vehicles is quite similar to the ones highlighted above on businesses and heavy machinery or equipment. Vehicle owners or people who sacrifice children or any other sacrifice believe that it will take away the misfortunes mainly related to accidents and constant break downs with subsequent need for repairs. The bigger the vehicle the more valuable it is and hence the more valuable should be the sacrificial item. It is from this context that there is a widespread belief that children are usually sacrificed for heavy trucks like buses, trailers or road construction unit trucks. In relation to this, there is also widely held belief that more children have disappeared and most likely have been sacrificed due to the many road construction works currently going on in the country and more need for heavy trucks or trailers for inter-state road transport.

In terms of employment, it important to posit the explanation within the historical political economy context. According to Atekyereza (2011: Chapter eight), in most pre-colonial Africa and the rest of pre-industrial societies, every member of society was a worker with dignity in one way or another. Through or as part of each person's roles, an extended family-based social security system evolved to take care of those not yet able to work (the very young), those unable to work (mainly due to disability) and those who were too old to do heavy manual activities. Today, the transformation of the previously traditional subsistence agricultural household economy to a modern industrial commercial monetary global economy presents different distortions and contradictions in different regional, national and local economies. Whereas a section of the population may be self-employed, a more significant proportion has its livelihood 
based on wage or salary employment. Unemployment, therefore, causes not only economic but also social, cultural, psychological and even natural constraints, calamities and challenges. Once people are lucratively employed they want to keep their employment or even grow higher through promotion to higher positions of more responsibility, power, prestige and privileges. Those without employment are seriously searching for similar reasons. The sacrifice, and child sacrifice in particular is believed to catapult people into desired employment or higher and more lucrative positions of responsibility without much questioning by the employment or promotion body.

The treachery and fraud by traditional healers is also shrouded in economic incentives though strongly attached to people's cultures and value systems. Many people believe in supernatural powers. They believe that spirits of the dead relatives come back if not well buried. However, the desires of the supernatural powers and the spirit world are believed to be intelligible through specially talented or trained people and this is where the traditional healers come in. Some individuals are, therefore, interested in knowing what to do to appease the gods or spirits for protection, good luck, blessings and fortune. This creates a strong, binding and dependent relations between the traditional healers or the agents of gods and spirits and the believers to such an extent that believers will do anything they are told, including child sacrifice, either out of respect of fear of annoying the gods or spirits. It is this unquestionable obedient relationship that sustains criminal activities like child sacrifices.

To highlight this trickery and fraud, Hughes (2010: 3-4) reports how the ABC News team tried to learn more about the shadowy world of witchcraft in Uganda. Two reporters, a male and female, posed as a married couple building a hotel. The duo met the witchdoctor four times without a feedback and that each time the witchdoctor and his associates demanded for money. Hughes further reports "at the last meeting, we were summoned and told that our enemies have already resorted to human sacrifice. When we ask what we can do to fight this, we're told that the spirits are demanding that we come back the next day with \$1,500 and he will tell us what to do next. And if we don't take the next step, one of us will die". This clearly demonstrates how innocent children and persons die amidst the fraud system set in place by the traditional healers to trap their clients.

The more the dominant mode of production and consumption emphasises value of goods and services, the more likely the participants in such an economy are likely to adopt behaviour or practices believed to help them access, acquire, maintain or increase their economic wealth. The practice of child sacrifice is also borne out of this line of thought. A number of people make sacrifices in anticipation of such returns. Whereas it has been said that most people are requested to bring things like birds or animals of one colour, most preferably white, there are also those who have been said or are believed to have sacrificed children including their own children to receive various blessing or avert certain evil powers. There have been media reports of how people in very important offices of the land have visited the shrines and churches to seek for employment-related blessings. Some Pentecostal churches in Uganda today also use the concept of Okusiga i.e. to sow the seed for more fortunes which has a philosophy similar to that of sacrifice. This demonstrates that the desire for employment and above all lucrative employment is not the reserve of the un-employed or poor people. It is also in this line of thought that people believe in child sacrificing depending on what the medium or spirit consulted has commanded.

There is also another unconfirmed claim that wars also fuel different forms of sacrifice including human sacrifice like that of children. DeMause (2010) reiterates that human sacrifice is a human institution since all human culture has a belief in universal guilt and the need for ceremonies of sacrifice to repair the broken relationship between humanity and divinity. In this 
process the innocent is the child who is sacrificed for protection against death or injury during war. During the war there are economic gains particularly to those who gain control of vital resources especially natural resources. The media reports of the economic plundering of Democratic Republic of Congo during the war to remove President Mobutu Sese Seko and the persistence of the war in northern Uganda for over twenty years are two cases that attest to this conviction (Mugisa and Agencies, 2005). The human blood is believed to protect those involved in the war against the enemies or adversaries. Hence, the struggle to succeed in war and for the resultant economic gains has also been associated with sacrifices including child sacrifices. If this hypothesis is to be followed then potentially there is a correlation between the wars that have been raging in the Great Lakes region for the last two or so decades and the increasing levels of human and child sacrifice.

Given that child sacrifice is done for protection against anticipated future risks and losses, formal insurance would be the best alternative. However, instead of insuring their properties and businesses through the insurance sector, the business people rely more on superstition and belief in divine protection which involves human, including child, sacrifice. According to the men focus Group discussion held in Oyam in northern Uganda (as cited in EACO Uganda n.d.) "...they say if you don't sacrifice a child while constructing a big building, you will not live in that house for long because the gods will be demanding until you finally die...". (FGD Men, Oyam) or as the boda boda cyclists reported "You cannot construct a building to its completion and have it make money without pouring blood in it. I do not think so myself" (FGD Boda boda cyclists, Masaka). The insurance is not fully developed and hence sacrifice of children becomes an indemnity to prevent against future losses of wealth (EACO Uganda n.d.).

It is also reported that even some of the few insurance companies are believed not to be transacting their businesses genuinely but also part of the capital or material accumulation for personal and economic gain as reflected in media reports over unpaid or delayed payment of compensations from Insurance companies (Ssempijja, 2013 and Kulabako, 2013). Such experiences make people in the contemporary modern scientific world divert from scientific rationality and acceptable legal forms of social, human and economic protection to human sacrifice and child sacrifice in particular to protect their economic wealth or health. Therefore, the nature of the market and the beliefs of the population have provided leeway to conmen and fraudsters to make empty promises to their clients in exchange for money and other goods.

This also explains why people will see science as not enough to get things done. Even when it is well known that science works, such people believe that after the sacrifice including child sacrifice science will work even better. People believe that there are incidents that happen and cannot be explained using science. Over five years ago, during a personal conversation, there was a claim that cosmic forces affect the scientifically constructed machines like vehicles. According to this conversation, "a family was going for burial of their relative outside Kampala and when they boarded the vehicle from Kampala and travelled for a few kilometres, the vehicle suddenly stopped. The vehicle was checked for any mechanical fault and nothing was found. When the mourners decided to go back to Kampala the vehicle worked well as if it had never had any problem. On making a U-turn again to go for burial, the vehicle refused again!" It is such things that make some people believe that there is some other power beyond the science. It is also known that when people are going for burial, the vehicle that takes the dead body normally has all the four or all tyres go over eggs to avert any accidents or incidents like that described above. Other people offer sacrifices in form of prayer because it is believed that if the spirit of the dead has any unsettled issues with some of the living, it may try to harm them. Hence, there is a belief that powers over such forces can only be accessed through the use of non-orthodox scientific methods and processes including rituals like child sacrifice. In such 
cases, whether the correlation between the sacrifice and the results are scientific is irrelevant. What becomes relevant is whether the anticipated results are real to the believer in the sacrifice including child sacrifice.

\section{CONCLUSIONS}

The practice of human and child sacrifices, just like all other forms of sacrifice, have a long history of practice among different communities for different reasons whether logical and scientific or not. From the discussion, it is evident that sacrifices in themselves are not economic. The sacrificial items are goods of great economic exchange in the sense that they bring economic returns to those involved in the transaction. The processes that may lead to the acquisition and at times sacrificing of child may be coated in economic motives both on the side of traditional healers or their agents and those seeking favours. There are direct economic gains from the kidnap and sale of persons or children for human and/or child sacrifice. The economics of child sacrifice therefore may not be based on the direct economic or financial gains but on the beliefs and faiths in the outcome of the sacrifices made particularly in terms of creating more or lucrative opportunities and casting away the evil spells for the likely misfortunes. However, there is no scientific evidence that relates the anticipated economic returns to the form of sacrifice including child sacrifice. The relationship is a syllogistically logical and based on individual person's experiences. As Sorokin classically analysed, there are different cultural mentalities or outlooks on socio-economic and political life which co-exist at any one particular point in the society's history. However, only one cultural mentality is more dominant than others at a particular time as the other two remain salient. Hence, though the modern world is dominated by science and formalistic way of life, there is the metaphysical perception or conviction that human or child sacrifice is a source of blessing or protection in spite of the existing formal insurance system. The question that remains then is why such perceived syllogistic logical relationship between child sacrifice and economic gains continue spreading wide across many societies even at this point in history and how they can be stopped.

\section{References}

[1] Achebe Chinua, Things Fall Apart: London: Heinemann, 1958.

[2] Achebe Chinua, No longer At Ease: London: Heinemann, 1960.

[3] Alvarez Sharon A., Rajshree Agarwal and Olav Sorenson, Handbookfor Entrepreneurship Research: Interdisciplinary Perspectives; Birkhäuser, 2009.

[4] ANPPCAN Uganda Chapter, Statement at a Press Briefing During the Launch of the Child Abuse Awareness Week, June 82009.

[5] Atekyereza Peter, Changing Family Life in Uganda: Analysis of Family Forms and Functions among selected Ethnic Groups: Saarbrüken, Germany: Lambert Academic Publishing, 2011.

[6] Bradley L. Roberts Jr, Capitalism at Work: Business Government and Energy: M\&M Scrivener Press, 2009. 
[7] Carlin W., Haskel J. and Seabright P., Understanding the Essential Fact about Capitalism: Markets, Competition and Creative destruction, National Institute Economic Review 175 (2001) 70-87.

[8] Chang Han-Joon, 23 Things They Don't Tell You about Capitalism: London, New York, Toronto, Dublin, Victoria, Auckland and Johannesburg: Penguin Books Ltd, 2010.

[9] Coser Lewis, Masters of Sociological Thought: Ideas in Historical and Social Context, $2^{\text {nd }}$ Ed: Florida: Harcourt Brace Jovanovian Inc., 1977.

[10] DeMause Lloyd, The Origins of War in Child Abuse: New York: Creative Roots, 2010.

[11] Empower and Care Organisation (EACO) Uganda, Working to Abolish Child Sacrifice in Uganda: Website: From http://www.asafeworldforwomen.org/partners-in-africa/ partners-in-uganda/eaco/studies.html (downloaded on Monday, February 04, 2013).

[12] Economic Glossary, Economic Definition of Wealth, 2008. Permalink: http://glossary.econguru.com/economic-term/wealth

[13] Finegan P., Philippine Islands, In The Catholic Encyclopedia: New York: Robert Appleton Company, 1911. Retrieved March 18, 2013 from New Advent: http://www.newadvent.org/cathen/12010a.htm

[14] Guralnik David Bernard, (Editor in Chief) Webster's New World Dictionary of the American Language, 2nd College Edition. New York: New Wold Dictionaries/Simon and Schuster, 1986.

[15] Hughes Dana, Child Sacrifice Emerges as Disturbing Trend in Uganda: ABC News reported on February 25, 2010. Website: http://abcnews.go.com/2020/child-sacrifice uganda-witch-doctors-spread-belief/story?id=9930029 (downloaded on Monday, February 04, 2013).

[16] International Bible Society, The Holy Bible: New International Version: New Jersey; International Bible Society, 1984.

[17] Kulabako Faidah, "Ignorance costing motorists insurance benefits": The Daily Monitor Newspaper of Tuesday, March 12, 2013. Website: http://www.monitor.co.ug/Business/Prosper/Ignorance-costing-motorists-insurancebenefits-/-/688616/1717330/-/645d2az/-/index.html (downloaded on March 18, 2013).

[18] Mmumuhungirehe Siriveeriyo, Ekyeba Juba n'Obworo n'Obugumba. Mbarara: Omuhanda gw' Okumanya, 1984.

[19] Mugisa Anne and Agencies, "DR Congo Plunder Case hearing Starts": New Vision Newspaper of April 11, 2005. Website: http://www.newvision.co.ug/PA/8/12/428673 accessed 1/17/2012 9:52:34 AM.

[20] Narasimha Murthy A.V., Human Sacrifices and Dams, 1998. Website: http://www.ourkarnataka.com/Articles/starofmysore/hsacrifice09.htm (Downloaded on Monday, March 18, 2013).

[21] Nsambu Hillary and Ali Mambule, "Ritual murder suspect Kajubi acquitted": New Vision Newspaper of April 24, 2010. Website: http://www.newvision.co.ug/D/8/12/717319 accessed 1/16/2012 5:39:40 PM.

[22] Nzita R. and Mbaga N., Peoples and Cultures of Uganda 3rd Ed: Kampala: Fountain Publishers Ltd, 1997. 
[23] Online Reporter, "Police Hunt for Kampala Tycoon Kajubi”: New Vision Newspaper of September 10, 2011. Website: http://www.newvision.co.ug//D/8/12/765555 accessed 1/16/2012 4:41:42 PM.

[24] Ritzer George, Sociological Theory: New York: MacGraw-Hill, Inc., 1992.

[25] Ritzer George and Douglas J. Goodman, Sociological Theory, $6^{\text {th }}$ Edition: Boston, etc.: McGraw-Hill Inc., 2004.

[26] Ssempijja David, "Customers, Insurers clash over third party": The New Vision Newspaper of $18^{\text {th }}$ March 2013. New Vision Publications Ltd. Website: http://www.newvision.co.ug/mobile/Detail.aspx?NewsID=630116\&CatID=3 (downloaded on Monday, March 18, 2013).

[27] Vernaschi Marco, Child Sacrifice in Uganda, 2010. Available at: http://pulitzercenter.org/slideshows/child-sacrifice-uganda-0 (downloaded on Monday, February 04, 2013).

[28] Winkelman Michael, Aztec Human Sacrifice: Cross-cultural Assessments of the Ecological Hypothesis, Ethnology 37(3) (1998) 285-298. 